\title{
Archives of Oral and Maxillofacial Surgery
}

\section{A Rare Case of Peripheral Ameloblastic Fibroma: Case Report}

\author{
Sang Woo Kim, DDS ${ }^{1^{*}}$, Keith Sonneveld, $D D S^{1}$, Minou Luo, $D M D^{1}$ and Jason Portnof, DMD, MD $D^{2,3}$ \\ ${ }^{1}$ Resident, Oral \& Maxillofacial Surgery, Nova Southeastern University-College of Dental Medicine, USA \\ ${ }^{2}$ Associate Professor, Director, Pediatric Maxillofacial Surgery \& Craniomaxillofacial Surgery, Nova Southeastern \\ University-College of Dental Medicine, USA \\ ${ }^{3}$ Attending Physician, Joe DiMaggio Children's Hospital, USA
}

\begin{abstract}
Ameloblastic fibroma (AF) is an uncommon mixed benign odontogenic tumor that usually presents in the first two decades of life with no predilection for sex or race. It can present either peripherally or centrally with a majority of the cases presenting in the posterior mandible. Although it usually presents in posterior mandible, we present a case of a peripheral AF in the maxillary anterior gingiva, which has been described rarely in literature. Described are the clinical, radiographic and histologic features and the subsequent surgical treatment for this lesion.
\end{abstract}

\section{Introduction}

Ameloblastic fibroma (AF) is an uncommon tumor representing $2.5 \%$ of all odontogenic tumors [1-3]. Although most are central, there have been reports of peripheral (soft tissue) ameloblastic fibro as $[4,5]$. They present most commonly in children and young adults as an asymptomatic, slow growing mass. The majority of these lesions present in the posterior mandible and are associated with an impacted tooth $[5,6]$. From an exhaustive literature review, only four tumors have been reported in the anterior maxillary region [2,3]. A case is presented of a 19-month-old with AF associated with tooth \#E.

\section{Case Report}

A 19-month-old boy was referred to the Oral and Maxillofacial Surgery department at Nova Southeastern University-College of Dental Medicine in August 2018 for diagnosis of a lesion associated with primary tooth \#E. His father initially became concerned 6 months prior when a mild red swelling from edentulous site \#E started to become noticeable. His father noted that the patient's remaining dentition had erupted. Patient was referred to the pediatric dentist, who decided to monitor the lesion with reimaging during the 6 months. During that time, the tooth was exposed through the gingiva but has not fully erupted into position. Mild swelling persistently remained localized around tooth \#E. The lesion had slowly grown in size and has now caused displacement of erupted tooth \#E. Father denies any recent trauma to the patient's mouth. His medical, surgical and family histories were unremarkable. Remaining physical exam showed no abnormalities as well.
Intraoral examination revealed a $5 \times 5 \mathrm{~mm}$ swelling directly palatal to tooth \#E (Figure 1). Lesion was firm, non-mobile, non-tender with no evidence of pus or bloody discharge from swelling. The overlying gingiva was ulcerated, brownish-white in color with well-defined borders. It was obvious that this lesion was also displacing tooth \#E buccally while also causing difficulty erupting compared to the contralateral tooth \#F. No other intraoral lesions were noted.

Serial anterior occlusal periapical radiographs were tak-

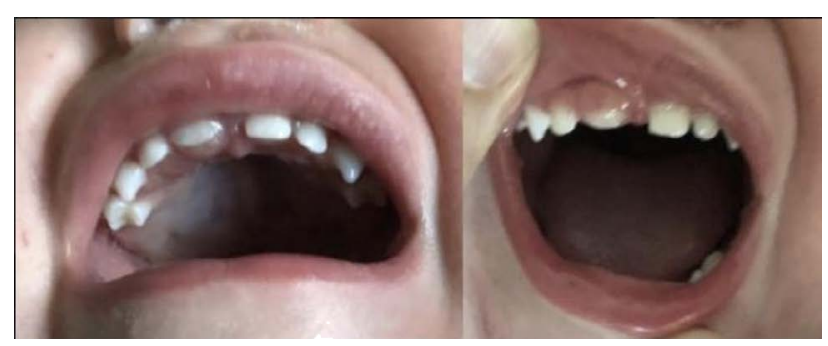

Figure 1: Clinical photos of tooth $\mathrm{E}$.

*Corresponding author: Sang Woo Kim, DDS, Resident, Oral \& Maxillofacial Surgery, Nova Southeastern University-College of Dental Medicine, 3200 S. University Dr. Davie, FL 33328, USA, Tel: 909-202-2324, Fax: 954-355-5490

Accepted: June 08, 2020

Published online: June 10, 2020

Citation: Kim SW, Sonneveld K, Luo M, et al. (2020) A Rare Case of Peripheral Ameloblastic Fibroma: Case Report. Archives Oral Maxillofac Surg 3(1):33-35 


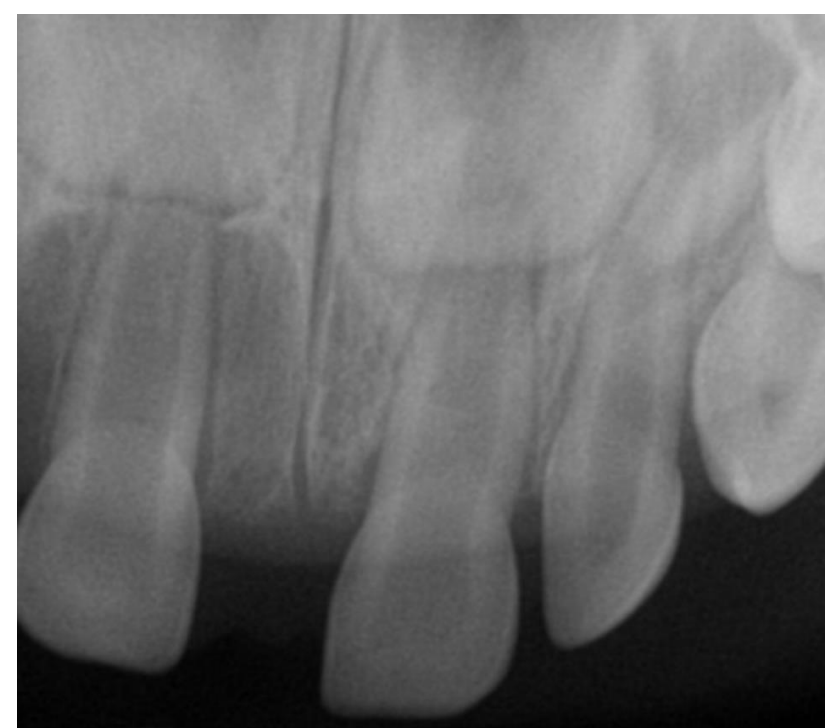

Figure 2: Periapical radiograph of tooth $\mathrm{E}$. There is a radiolucency surrounding the entire root of tooth $E$.

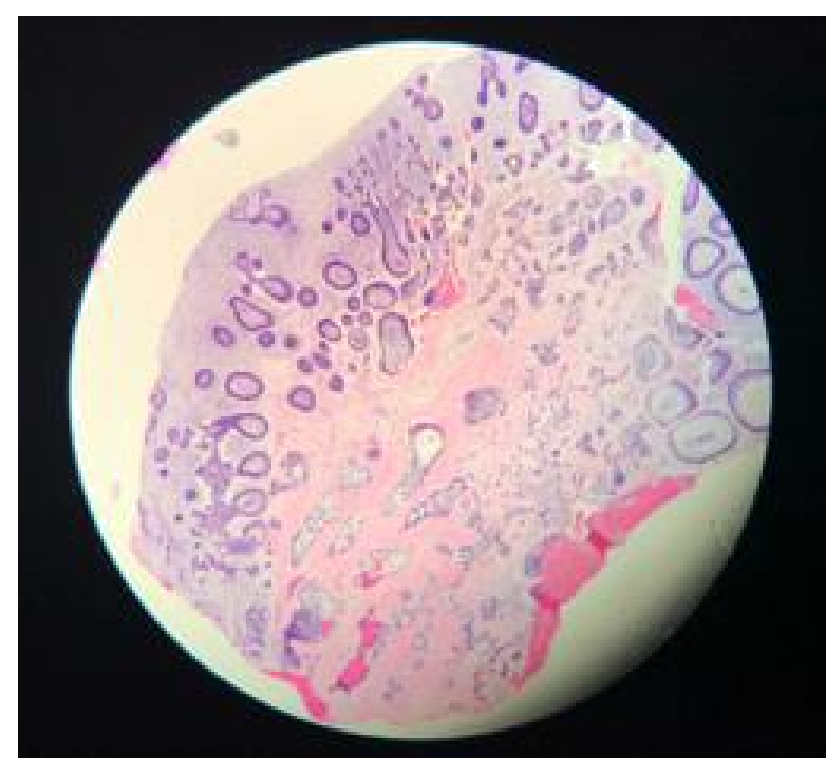

Figure 3A: Low power of magnification of tumor showing odontogenic epithelium arranged in cords, strands and nests while embedded in a hypercellular connective tissue stroma.

en prior to presentation to the clinic. The first radiograph showed a radiolucent lesion surrounding the crown and incomplete root formation of tooth \#E. Obvious difference in eruption of tooth \#E compared to tooth \#F was noted as well. In the most recent periapical film (Figure 2), no obvious bony involvement of the lesion was noted. Both primary central incisors seemed to be roughly symmetric with underlying permanent central incisors forming appropriately underneath. The clinical diagnosis of eruption cyst was made.

Under general anesthesia, the lesion was treated with enucleation and curettage, which included tooth $E$ as part of the specimen. The specimen was examined by the Oral \& Maxillofacial Pathology department at Nova Southeastern University-College of Dental Medicine.

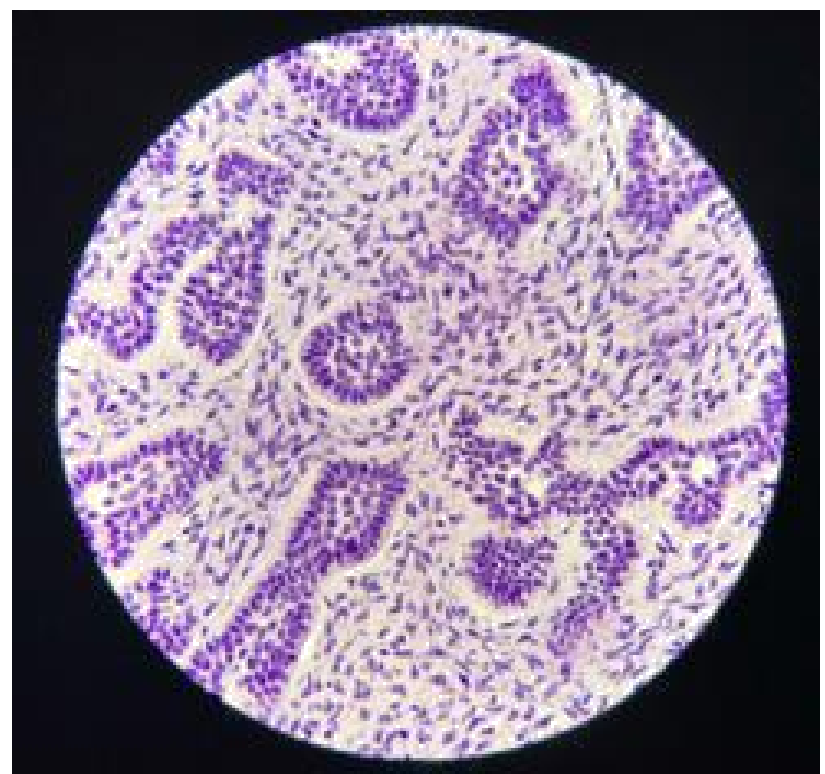

Figure 3B: Higher magnification reveals island of cuboidal to columnar odontogenic epithelium.

Histologically, the H\&E stains of lesion showed fragments of ulcerated mucosa partially covered by thin squamous epithelium (Figure 3A and Figure 3B). The lamina propria was composed of fibrous connective tissue largely replaced by cell-rich myxoid mesenchymal tissue and contained discrete islands and cords of odontogenic epithelium. These islands exhibit peripheral columnar cells surrounding loosely arranged epithelial cells resembling stellate reticulum. Fragments of vital bone were also noted.

Post-operatively, patient healed uneventfully and no recurrence was noted in an approximate 6 month follow-up interval.

\section{Discussion}

Ameloblastic fibroma is a benign mixed neoplasm of odontogenic origin with both epithelial and mesenchymal proliferation. The lesion was first described by Kruse in 1891 as a cystic lesion [3] and was later identified as its own separate entity by Thoma and Thompson is 1941 [7]. The precise etiology remains unclear [2]. It is believed to arise de novo during odontogenesis from hyperactive basal lamina without further odontogenic differentiation [2]. It is the least differentiated of the mixed odontogenic tumors because it does not produce any dentin or enamel matrix [2]. The two rare variants include granular cell and peripheral [2].

Ameloblastic fibromas are reported to occur between the ages of 7-weeks-old to 42-years-old [1,2] but most commonly present within the first two decades [2]. They present with no sex or race predilection $[2,6]$. Although case reports have shown AF to arise in unusual locations [6], they are predominantly present in the posterior mandible, where $80 \%$ of the lesion have been reported $[2,3]$. The incidence of recurrence after surgery ranges from $18-43 \%$ [1]. There have been reports indicating transformation of ameloblastic fibromas to its malignant counterpart--ameloblastic fibrosarcomas (AFS) 
$[8,9]$. In fact, close to $50 \%$ of all AFS are malignant transformation of $A F[3,8]$.

AF usually presents as an asymptomatic, slow growing mass [3]. It is reported that approximately $20 \%$ of cases are discovered accidentally on radiographs while attempting to diagnose an unerupted tooth [10]. Other more uncommon findings reported are pain, drainage and ulcerations [7]. Tumor sizes can vary from $1-8.5 \mathrm{~cm}$ [3]. They exhibit significantly slower growth than ameloblastoma and do not tend to infiltrate surrounding structures $[2,3]$. Instead, it tends to gradually expand and cause expansion or displacement of surrounding teeth [3]. Tumors are usually described as hard and firm [7].

Radiographically, AF presents as a uni- or multilocular radiolucent lesion and is most commonly associated with an unerupted tooth [3]. Unilocular lesions tend to be asymptomatic while multilocular lesions tend to exhibit more expansion of the jaws [7]. The borders of AF are well defined and corticated as it is a slow growing lesion [7]. When visualized with computer tomography (CT), AF may show expansion but no perforation of the cortices [1,3]. Other associated features include displacement and divergence of roots of adjacent teeth [7].

Microscopically, many similarities are seen between ameloblastoma and ameloblastic fibro as [11]. The odontogenic epithelium presents as strands, nests and cords of cuboidal or columnar cells with stellate reticulum developing in the central portion [3]. The cell rich mesenchymal component resembles a dental papilla. The connective tissue stroma is more dense and is what distinguishes AF from ameloblastoma [11]. Meanwhile, AF do not contain any enamel or dentin matrix, which separates AF from ameloblastic fibro-odontoma [7]. The presence of mitosis, nuclear polymorphism and hyperchromatism should raise concerns for ameloblastic fibrosarcoma [8].

Treatment of AF remains controversial with both conservative and radical approaches suggested by different authors $[1,3,12]$. No one method seems to be claimed as universal. Some authors recommend a wide local excision unless treatment results in significant cosmetic deformities [1]. Other authors reported enucleation and curettage at the initial appointment with an en-bloc resection if there is the presence of recurrence $[1,3]$. Treatment of $A F$ is most commonly enucleation and curettage [9]. Although there have been reports suggesting aggressive initial therapy [10], the majority of the articles published agree that these lesions should be treated conservatively [11]. Recurrent AF lesions on the other hand should be treated aggressively [10]. Long term follow up must be emphasized for at least 10 years [3].

In summary, this is a case of a rare peripheral ameloblastic fibroma that presents in the anterior maxilla. The peripheral variant can be treated with surgical enucleation and curettage followed by observation for clinical recurrence.

\section{References}

1. Pereira K, Bennett K, Elkins T, et al. (2004) Ameloblastic fibroma of the Maxillary Sinus. International Journal of Pediatric Otorhinolaryngology 68: 1473-1477.

2. Kim S, Jang H (2002) Ameloblastic fibroma: Report of a case. Journal of Oral and Maxillofacial Surgery 60: 216-218.

3. Mosby E, Russell D, Noren S, et al. (1998) Ameloblastic fibroma in a 7-week old infant: A case report and review of the literature. Journal of Oral and Maxillofacial Surgery 56: 368-372.

4. Kasuma K, Miyake M, Moro I (1998) Peripheral ameloblastic fibroma of the mandible: Report of a case. Journal of Oral and Maxillofacial Surgery 56: 399-401.

5. Abughazalah K, Andrus KM, Katsnelson A, et al. (2008) Peripheral ameloblastic fibroma of the maxilla: Report of a case and literature review. Oral Surgery, Oral Medicine, Oral Pathology and Oral Radiology 105: e46-e48.

6. Corte AF, Moura CF, Filipe JP, et al. (2018) Ameloblastic fibroma with an unusual location. Otology \& Neurotology 39: e1176-e1178.

7. Chen Y, Wang JM, Li TJ (2007) Ameloblastic fibroma: A review of published studies with special reference to its nature and biological behavior. Oral Oncology 43: 960-969.

8. Bertoni F, Corso GD, Patrizia Bacchini, et al. (2016) Ameloblastic fibrosarcoma of the mandible, evolving from a prior ameloblastic fibroma after two years: An unusual finding. International Journal of Surgical Pathology 24: 656-659.

9. Celik O, Yalcin S (2007) Ameloblastic fibroma of the maxilla. British Journal of Oral and Maxillofacial Surgery 72-73.

10. Ravikumar S, Sarkar A, Goyal S (2013) Recurrent ameloblastic fibroma: Report of a rare case. Case Reports in Dentistry: 565721.

11. Dallera P, Bertoni F, Marchetti C, et al (1996) Ameloblastic fibroma: A follow up of 6 cases. International Journal of Oral \& Maxillofacial Surgery 25: 199-202.

12. Vasconcellos SJ, Santos T, Savil Costa Vaaez, et al. (2015) Massive ameloblastic fibroma treated with surgical conservative treatment. The Journal of Craniofacial Surgery 26: 999-1000.

DOI: $10.36959 / 379 / 352$

Copyright: (C) $2020 \mathrm{Kim}$ SW, et al. This is an open-access article distributed under the terms of the Creative Commons Attribution License, which permits unrestricted use, distribution, and reproduction in any medium, provided the original author and source are credited. 